\title{
Colony-Stimulating Factor Therapy
}

National Cancer Institute

\section{Source}

National Cancer Institute. Colony-Stimulating Factor Therapy. NCI Thesaurus. Code C15515.

The use of colony-stimulating factor to increase leukocyte production in the treatment of any disease or disorder. 